\title{
Understanding the effects of hooked-end steel fibre geometry on the uniaxial tensile behaviour of self- compacting concrete
}

\author{
Sadoon Abdallah*, David W.A. Rees, Seyed Hamidreza Ghaffar and Mizi Fan
}

College of Engineering, Design and Physical Sciences, Brunel University London Uxbridge, UB8 3PH, London, United Kingdom

\begin{abstract}
A series of uniaxial tensile tests on cylinders made from steel fibre reinforced selfcompacting concrete (SFR-SCC) have been carried out to investigate the influence of fibre geometry and the combined effect of fibre content and distribution on the post-cracking behaviour. Three types of commercially available hooked end fibres (3D (single hooked), 4D double (double hooked) and 5D (triple hooked )) have been used in this study, which are added to the concrete mixture at two fibre dosages ( 0.5 and $1 \%$ by volume). The experiments show that the post-cracking strength increases significantly $(P<0.05)$ with the increase of fibre content for all mixtures. The combination of a unique shaped hook of high tensile strength demonstrates an optimum effect on the failure mode of concrete cylinders in which peak and post-peak strengths are raised. Notably, strain-hardening behaviour is observed only for cylinders reinforced with 5D hooked end fibres. A correlation between number of fibres exposed on fractured surfaces and post-cracking behaviour is established.
\end{abstract}

Keywords:

Post-cracking behaviour; Self-compacting concrete; Hooked end fibres; Uniaxial tensile test; Hook geometry.

*Corresponding author: Sadoon Abdallah, Email: sadoon.abdallah@gmail.com 


\section{Introduction}

There is a rising interest in utilising steel fibre reinforced self-compacting concrete (SFRCSCC) in modern structural applications [1,2]. This is because of its appealing physical and mechanical properties, which in some applications could replace partially or completely the conventional rebar or mesh reinforcement $[3,4]$. Plain concrete is known for its weakness normal to a tensile force direction leading to its brittle fracture in tension [5-8] as soon the first crack appears. In SFRC after the peak load is reached a post-cracking plateau will occur that results from continuous pull-out of the fibres. The fibre contribution is not obvious until the occurrence of the first micro-crack in the concrete $[9,10]$. The post-cracking behaviour of SFRC can be conveniently categorised based on its tensile behaviour by either strainsoftening or strain hardening [11]. The strain-softening of SFRC exhibits a low stress-strain response due to crack localisation instantly after first cracking. On the other hand, the strain hardening of SFRC is generally characterised by hardening behaviour after first cracking occurs, immediately followed by multiple cracking [12].

The randomly distributed and oriented steel fibres in the concrete can resist micro-cracking at an early stage. The post-cracking response of SFRC is strongly dependent on the bond quality between steel fibres and their cementitious matrix [13-15]. The shape, length and orientation of the fibre determine whether the fibre will break or be pulled-out. An efficient load transfer from the concrete into the steel fibres will result in a high tensile stress; the longer steel fibres will be more efficient at bridging the crack. Besides the shape and length, steel fibre needs to have a high tensile strength in order to resist fibre rupture. In the post cracking behaviour, the steel fibre with a high load resisting capacity, assures an increased degree of ductility. Over the past five decades, different shapes and geometries of steel fibres have been introduced to increase the crack-bridging capacity provided by fibres. These include crimped, straight, spiral, hooked end and twisted [16,17]. However, according to the last statistics, two thirds of steel fibres used in concrete are hooked end fibres of single hooked (3D) compared with other types $[18,19]$. Dramix hooked end steel fibres of improved geometry, namely 4D (double hooked) and 5D (triple hooked) were recently introduced and currently are used extensively in concrete structural applications. These fibres are designed to increase the capacity of a concrete structure to bear complex loading including tension, compression, and shear[20,21]. 
The characterization of the tensile behaviour of SFRC has been largely investigated, particularly during the last few decades, where the interest of using SFRC in the structural applications became more evident[22-25]. However, the lack of comprehensive and detailed international standards on the fundamental properties of SFRC is the main reason behind the underutilisation in engineering practice so far. Due to involve a large number of parameters governing tensile behaviour of SFRC make materials modelling a complex task[26,27]. Different approaches can be found in the literature to model tensile behaviour of SFRC. Among these several proposals associated with modelling methodologies are: (1) Stress-crack width law and stress-strain law, (2) Inverse approach and direct approach, (3) Micro-scale and macro-scale research levels, and (4) Continuously differentiable and continuous non-differentiable diagrams. The earlier guidelines to characterise post-cracking response of SFRC were proposed by $\mathrm{ACl} 544$ [28] and $\mathrm{ACl} 318$ [29], which contain some design considerations with reference to minimum shear reinforcement, whereas design guidelines produced by RILEM TC162-TDF [30] were introduced some new rules for typical structural elements. Later, recommendations and guidelines for SFRC design were produced by Some Europe countries, e.g. Italian (CNR-DT 204,2006) [31], Germany (DAfStb, 2007) [32] and Spanish (EHE, 2008) [33]. These are adopted both a simplified and continuous nondifferentiable constitutive diagrams whose parameters can be derived from the inversed analysis.

Recently, some international building codes and national guidelines for the structural design of SFRC, such as fib Model Code 2010 have been developed in response to this limitation. However, even though these relevant advances have recently been drawn up, some basic aspects still open questions and feed doubts on the uniaxial tensile constitutive relationships proposed by various international recommendations and guidelines. Further studies are still needed to provide in-depth and comprehensive knowledge on the tensile behaviour of SFRC and serve as the basis possible for better design and future codes.

Several methods have been proposed to investigate the post-cracking behaviour of SFRC; the most widely used being uniaxial tensile and flexural tests $[4,18,34-36]$. The majority of the experimental studies of tensile behaviour in SFRC have employed the former test [37]. The tensile test is probably the one test that provides all the relevant fracture parameters directly [38], providing basic information on the tensile response of SFRC, from which a 
relation between section stress and crack width is derived directly [39]. Different configurations of the uniaxial tensile test, either in terms of the specimen's geometry (i.e. dog bone, cylinders with different dimensions) or with regards to the testing procedure (i.e. different gripping systems and set ups) have been tried. However, there is no standard method for uniaxial tensile test, but, a useful guideline for testing SFRC with post peak stress softening has been proposed by RILEM TC162-TDF [40].

The main intention of this paper is to investigate the tensile behaviour of 3D, 4D and 5D hooked end steel fibres through uniaxial tensile tests. The results of experiments are essential in order to provide fundamental information for efficient exploitation and application of especially 4D and 5D hooked end steel fibres. These results will then contribute to a better understanding of the bond mechanisms, which can lead to the optimization of SFR-SCC and serve as a basis for possible better design and application of steel fibres.

\section{Experimental program}

\subsection{Materials and sample preparation}

For the experimental sample preparations the following materials were used: 1) Ordinary Portland Cement $(52.5 \mathrm{~N})$ complying with the requirements of British Standards BS EN 197-1: $2000,2)$ Fly ash with a particle size in the range of $0.02-0.20 \mu \mathrm{m}$ and the specific surface area of $11.148 \mathrm{~m}^{2} / \mathrm{kg}, 3$ ) River sand in the range of $0-4 \mathrm{~mm}$ as fine aggregate and crushed granite having a maximum size of $10 \mathrm{~mm}$ as coarse aggregates, and finally 4). A new generation of polycarboxylate-based superplasticiser having a specific gravity of $1.07 \mathrm{~kg} / \mathrm{m}^{3}$ and chloride ion content $<0.01 \%$ was also used to enhance the workability of mixes. The mix proportions used in this study are summarised in Table 1.

Three types of commercially available Dramix (Belgium) hooked end steel fibres were investigated for this study. These fibres are designated according to the manufacturer hook geometry as 3D (single hooked), 4D (double hooked) and 5D (triple hooked). The geometrical and mechanical properties of all fibres are depicted in Fig. 1 and detailed in Table 2. Each of these fibres was added to the concrete mixture at two dosages i.e. 40 and $80 \mathrm{~kg} / \mathrm{m}^{3}$, corresponding approximately to a volume fraction of 0.5 and $1 \%$, respectively. 
During mixture preparation, the dry materials i.e. cement, fly ash, and aggregates were firstly mixed for 1 minute before the superplasticizer and water were added. This solution was then mixed for another 7 minutes. To prepare for the fibres, the mixing was continued for another 3-6 minutes where $25 \%$ of water was kept and added in this second stage to ensure a more homogenous mix (Fig. 2). The freshly prepared SCC and SFR-SCC were cast into $150 \times 300 \mathrm{~mm}$ cylindrical moulds conforming to RILEM TC 162-TDF (see Fig. 3a) [40]. All specimens were casting by using of plastic pails and filling of the entire mould and then top surfaces were smoothly levelled. The specimens were instantly covered with polyethylene sheets to prevent moisture loss and demoulded after $24 \mathrm{~h}$ in a curing condition chamber at a temperature of $22 \pm 2^{\circ} \mathrm{C}$ and relatively humidity of $95 \%$ until the age of testing. Both the nominal length and diameter of the specimen should be equal to $150 \mathrm{~mm}$ (Figs. 3a and 3(b3)). To obtain these dimensions, the top and bottom of the specimen were sawn off at a distance of $75 \mathrm{~mm}$ (Fig. 3b1). A circumferential notch with a width of 2-5 mm and a depth of $15 \mathrm{~mm}+/-1 \mathrm{~mm}$ was made at mid-position of the specimen to ensure crack localisation during the tests (Fig. 3(b2)). Special care was given during the cutting process to guarantee smooth surface and perpendicular plane to the cylinder axis.

\subsection{Set-up and test procedures}

\subsubsection{Uniaxial tensile test}

Following the cutting and notching process, all specimens were carefully cleaned with pressurized air and acetone. Afterwards, two metal plates attached in the loading cell were glued using ultra performance adhesives (Epoxy), to the top and bottom surfaces of the specimen, which was then left to cure for two hours before testing (Fig .4). The balance and load-centering device were used in the test setup.

An Instron 2670 series testing machine of $150 \mathrm{kN}$ loading carrying capacity was used to perform the uniaxial tensile tests. This test was carried out under closed-loop displacement control in which the averaged readings of three displacement transducers arranged around the perimeter of the specimen were measured. The three displacement transducers had a $30 \mathrm{~mm}$ travel. The displacement rates adopted were as follows: $5 \mu \mathrm{m} / \mathrm{min}$ up to a displacement of $0.1 \mathrm{~mm}$ and $100 \mu \mathrm{m} / \mathrm{min}$ up to a displacement of $2 \mathrm{~mm}$. This was continued until a crack width of $10 \mathrm{~mm}$ was attained in order to ensure that the hook part of each fibre was fully deformed and straightened. The testing procedure adopted and displacement 
rates complied with the recommendations of RILEM TC 162-TDF [40]. For each tested series, the average value of 6 specimens was adopted.

\subsubsection{Rheological and compressive characterisation}

To investigate the effect of the incorporation of steel fibres on self-compatibility properties, slump flow and V-funnel tests were performed for each mixture according to standards $[41,42]$. A mixture is only considered as self-compacted when having a slump flow diameter ranging from 500 to $700 \mathrm{~mm}[43,44]$. V-funnel test provides information on the passing and filling ability of mixture. In this test, the V-funnel flow time is recorded and if blockage occurs the mixture cannot be considered to be self-compacting.

The compressive strength tests on a $150 \mathrm{~mm}$ cube specimen conformed to BS EN 1971:2011[45] using a $3 \mathrm{MN}$ compression machine. For each mixture, five specimens were tested at an age of 28 days, for which the average load versus displscement curve is reported.

\subsubsection{Pull-out strength test}

The single fibre pull-out tests were performed using a specially designed grip system, as illustrated in Fig. 5, which was attached to an Instron 5584 universal testing machine. The grips were designed such that the force applied to the fibre would represent that in a fibre bridging a crack. The body of the gripping system was machined in a lathe using mild steel and had a tapered end to allow the insertion of four M4 grub screws (Fig. 5). These were then tightened around the steel fibre to an equal torque for an even distribution of gripping pressure to minimise the deformation of the fibre ends and avoid breakage at the tip. Two linear variable differential transformer (LVDT) transducers were used to measure the distance travelled by the steel fibre relative to the concrete face during testing (i.e. the pullout distance). They were held in place using aluminium sleeves on either side of the main grip body (Fig. 5). The LVDT probes had ball bearings at their tips for accuracy in measurements taken from the top datum face. The sample was secured to the Instron base using clamps with riser blocks and M16 studs. The base rested on a round brass disc to retain flatness under test at a displacement rate of $10 \mu \mathrm{m} / \mathrm{s}$. In all pull-out tests, an average value of 9 specimens was adopted. 


\subsection{Results and Discussion}

\subsection{Rheology, compressive and bond-slip characteristics of self-compacting mixture}

In order to examine the flowability and flow rate characteristics of plain SCC and SFR-SCC mixtures, slump flow and V-funnel tests were carried out. In Table 3, SFD represents the slump-flow diameter, $T_{500}$ represents the time to reach $500 \mathrm{~mm}$ spread and $T_{v}$ represents the $V$-funnel flow time. It can be seen that the addition of steel fibres slightly decrease the workablity of all mixtures. However, all the steel fibres mixtures meet the requirements of self-compacting properties which is more than $500 \mathrm{~mm}$ flow and when the mixture doesn't stick to the V-funnel.

The average cube compressive strength of each mixture with their relative density and the coefficient of variation are also presented in Table 3. As expected, it can be observed that the addition of steel fibres do not make much of an influence on the compressive strength of the samples, although, and again as expected, the fibre reinforced samples showed a much more ductile behaviour during failure compared to plain ones.

The bond-slip characteristics at the fibre/matrix interface are commonly investigated by means of a single fibre pullout test $[3,46]$. Initial mechanisms governing the pull-out behaviour of hooked end fibres are similar to those measured for straight fibres (i.e. debonding, followed by frictional pull-out). Here, however, the frictional pull-out is preceded by mechanical interlocking. To release the hook, all curvatures must straighten within plastic hinges. Thus, the fibre hook must undergo considerable plastic deformation, resulting in a substantial increase and maximum pull-out load. Beyond its maximum, the pull-out load starts to decrease due to the progressive mobilization and entrance of curvature into the straight part of the channel. When curvature has straightened, the wire moves into the straight part of the channel. Then moving and straightening of other curvatures result in a slight decrease in pull-out load. Once all curvatures are completely deformed and straightened, the pull-out load need only overcome kinetic frictional resistance as for a straight fibre. This phase prevails until the whole fibre is completely removed from the matrix.

The average pull-out-slip response of $3 \mathrm{D}, 4 \mathrm{D}$ and $5 \mathrm{D}$ fibres embedded in SCC matrix up to half fibre length i.e. $30 \mathrm{~mm}$ are presented in Fig. 6 . It can be seen that the pull-out load 
versus slip curve is formed from a sequence of events in which partial and full debonding at the interface is followed by bending of the hook knee to raise the load to its maximum. A loss of peak pull-out load occurs with the reversed plasticity involved in a full straightening of the fibre that precedes the rapid sliding to its full removal under a falling load. It is also interesting to notice from Fig. 6 that the pull-out behaviour of hooked-end fibres dramatically increase as hook ends increases i.e. 4D and 5D, where the 5D fibres show higher pull-out strength than the 4D and 3D fibres. For the 5D fibre, higher residual frictional reisistence can be observed compared with others. This occurs because the remaining irregularities due to incomplete deformation and straightening of the hook ends, together with the friction effect (present in coarse aggregates) lead to high residual strength. The analysis of pull-out mechanisms of these fibres has been explained in detail by Abdallah et al.[20].

\subsection{Stress-crack width response}

Stress-crack width response is measured according to RILEM TC 162-TD[40] up to the crack width of $2 \mathrm{~mm}$. The average tensile stress-crack width curves of plain concrete (PC) and reinforced concrete by different hooked end steel fibres are presented in Figs. 7 and 8 for a fibre content of 0.5 and $1 \%$, respectively. Figs. 7 (a) and 8 (a) show crack width up to $2 \mathrm{~mm}$ and Figs. 7 (b) and 8 (b) up to $0.1 \mathrm{~mm}$. It can be seen in Figs. 7a and 8a that concrete matrix (CM) exhibits almost linear behaviour up to the peak stress, which corresponds to crack width of about $0.08 \mathrm{~mm}$, followed by a sudden drop in stress at the initial stage of the postpeak response. For all plain concretes, a brittle failure was observed, accompanied by separation of the specimens at the notch into two parts. On the other hand, the specimens reinforced with steel fibres demonstrate not only significantly higher peak load, but also a plateau response in the post-peak part. The post-peak region of the stress-crack width curve is clearly different in case of each of the three fibres. It is evident that specimens reinforced with 0.5 and $1 \%$ of $5 \mathrm{D}$ fibres show stronger strain hardening behaviour compared to the other fibres.

Average peak and post-peak parameters for different crack widths are presented in Table 4. In this table, $\sigma_{\text {peak }}$ is the maximum tensile stress, $\delta_{\text {peak }}$ is the corresponding displacement at 
peak stress and $\sigma_{2000}$ is the stress at a crack width of $2000 \mu \mathrm{m}$. Clearly, it is seen that the peak $\left(\sigma_{\text {peak }}\right)$ and post-peak parameters $\left(\sigma_{2000}\right)$ increase significantly as the fibre dosage increases from 0.5 to $1 \%$ for all fibres. Indeed, this is because of more fibres available to bridge the cracks. Interestingaly, in the case of 5D fibres the percentage increase in the $\sigma_{\text {peak }}$ $(141 \%)$ and $\sigma_{2000}(163 \%)$ are much more significant than the 3D and 4D fibres, where the percentage increase in the $\sigma_{\text {peak }}$ is $68 \%$, and $76 \%$, respectively.

As expected, the geometry of fibres strongly influences the $\sigma_{\text {peak. }}$ The hooked end steel fibres with a higher number of ends i.e. 4D and 5D are more effective in improving the peak and post-peak response than that of single hooked, 3D. At a comparable fibre dosage, for instance $1 \%$, specimens reinforced with 5D fibres obtain a higher peak by (51\% and 90\%) compared to 4D and 3D respectivaly. The corresponding increase for post-peak are $85 \%$ and $86 \%$.

The higher $\sigma_{2000}$ values for 5D fibres is mainly due to i) the unique combination of high anchorage and ii) the high tensile strength of the fibres. Certainly, both aspects provide higher resistance to the pull out of fibres at larger crack widths. It is noteworthy that the fibre rupture at fractured sections was observed for the 3D fibres, while for the 4D and 5D fibres only partially deformed and straightened mechanisms were visible. The rupture of 3D fibres may occur due to their relatively lower tensile strength.

\subsection{Fracture energy}

The energy absorbed or fracture energy is a fundamental parameter commonly used to evaluate the advantageous effects of fibres in SFRC. The fracture energy is defined as the amount of energy absorbed during the failure of the specimen, which is calculated by the following expression [40]:

$G_{F}=\int_{w_{i}}^{w_{m}} \sigma_{w}(w) d w$

Where $G_{F}$ is the fracture energy per unit area $(N / m), \sigma_{w}$ is the applied stress $\left(N / \mathrm{mm}^{2}\right), w_{i}$ represents smallest value of crack opening $(w)$ in $\mathrm{mm}$, and $w_{m}$ is equal to $2 \mathrm{~mm}$.

The calculated fracture energy $\left(G_{F, 2000}\right)$ up to a crack opening of $2 \mathrm{~mm}$ for each fibre type at the various fibre dosages is summarised in Table 4 . While $G_{F, 2000}$ of plain concrete is found to be lower than $0.00025 \mathrm{~N} / \mathrm{m}, G_{F, 2000}$ of SFRC samples tends to be considerably higher. 
The comparison of the fracture energy of SCC reinforced by different hooked end steel fibres is shown in Table 4. As expected, the $G_{F, 2000}$ of all SFRC-SCC series increases as the fibre dosage increases. The percent increase in the $G_{F, 2000}$ of $3 D, 4 D$ and $5 D$ fibres is $52 \%$, $45 \%$ and $50 \%$, respectively when fibre dosage increases from 0.5 to $1 \%$. The $G_{F, 2000}$ of $5 D$ fibre is higher than those of 3D and 4D fibres by $126 \%$ and $88 \%$ for fibre content of $0.5 \%$, while, the corresponding increase for $1 \%$ is $121 \%$ and $92 \%$, respectively. The lower values of $G_{F, 2000}$ for the 3D fibres may be a result of the lower tensile strength of the fibres which leads to fibre rupture during the pull-out. These results highlight that energy dissipated to bridge cracks of SFR-SCC is to a great extent influenced by the balanced combination of fibre strength and anchorage geometry, especially at high fibre dosage. Fibres with multiple hook ends would provide a higher resistance to the pull-out, whereas fibres of single hook ends (3D) will provide a moderate or limited resistance to crack propagation. Such improvement in the $G_{F, 2000}$ for 4D and 5D fibres occurs mainly due to high energy absorbed to deform and straighten the hook ends during the de-bonding and pull-out process.

\subsection{Analysis of fibre distribution and numbers at the cracked sections}

To understand further the influence of the fibre content and fibre distribution on the stresscrack width response, the total number of fibres visible on the fractured surfaces was counted to investigate a further relationship for post-cracking behaviour. Therefore, the cross section of the cylinder is divided into four different locations $(A, B, C$, and $D)$ as shown in Fig. 9, whereby the results of the distribution and number of fibres counted in different locations for each specimen are tabulated in Table 5. It is noteworthy that the number of effective fibres ( $\mathrm{N}_{\text {eff }}$ ) is only counted when the hook is partially or completely straightened. Additionally, the ruptured fibres visible on cracked sections are also regarded as effective, since they offer resistance to cracking against fibre slippage up to their failure. From visual inspection of fractured surfaces, the fibre rupture is only observed for 3D fibres (see Fig. 10).

As it can be observed from Table 5, the highest density of fibres is almost uniformly distributed in the locations $A, B, C$ and compared to the lowest in the location D, for all fibres series. It is clear that as the fibre content increases the total number of fibres $\left(N_{\text {total }}\right)$ counted on the fractured surfaces is also increased. However, the number of effective fibres $\left(\mathrm{N}_{\text {eff }}\right)$ could decrease when fibre dosage increases. This may occur due to the pulling out of a 
group of fibres simultaneously (group effect), hence, reducing the efficiency of fibres. Moreover, the efficiency of the fibre can also be reduced with increasing the number of the hook ends which results in a lower number of $N_{\text {eff. }}$ The 4D and 5D fibres have the lowest number of $\mathrm{N}_{\text {eff }}$ compared with 3D fibres. This indicates that less energy is invested to deform the hook ends of $4 D$ and $5 D$ fibres during the pull-out. The reason for this observation can be due to the concrete strength which is not high enough to create high anchorage strengths needed for 4D and 5D fibres. Therefore, concrete with ultra-high strength would ensure a better quality interface and subsequently more energy is absorbed by the hook ends of these fibres during pull-out.

\subsection{Relationship between fibre distribution and post-cracking behaviour}

To understand better the post-cracking behaviour of SFR-SCC, the correlation between the average numbers of fibres counted on the fractured surfaces and post-cracking parameters was analysed. The relationship between the maximum tensile stress $\left(\sigma_{\text {peak }}\right)$ with $\left(N_{\text {total }}\right)$ and $\left(\mathrm{N}_{\text {eff }}\right)$ on the fracture surfaces for all specimens are presented in Figs. 11-13.

It can be seen that an almost linear correlation can be traced between $\sigma_{\text {peak }}$ and $N_{\text {total }} / N_{\text {eff }}$ parameters, which is in agreement with other results reported previously $[37,47]$. The $\sigma_{\text {peak }}$ is closely related to the $\mathrm{N}_{\text {eff, }}$ with the exception of 5D fibres series. For this series (Fig. 13), no clear trend can be identified between the $\sigma_{\text {peak }}$ and $N_{\text {eff, }}$ which provides the lowest coefficient of determination $\left(\mathrm{R}^{2}\right)$ of 0.21 (Fig. 13b). This discrepancy may be a result of variability in the deformation and straightening level of hook ends due to incompatibility between high anchorage strength of 5D fibres and concrete strength, i.e. interfacial bonding. A high variability of this implies a large scattering (coefficient of variation) in the $\sigma_{\text {peak }}$ as shown in Table 4. Generally, the scattering in $\sigma_{\text {peak }}$ for 4D and 5D fibres appears higher than the peaks observed for the 3D fibres (Table 4).

Interestingly, as previously observed above, the $\sigma_{\text {peak }}$ and $G_{F, 2000}$ of higher dosage fibre contents and 4D, 5D samples illustrate a contrary phenomenon in that they show higher strengths. This is in part due to the higher tensile strength of $4 \mathrm{D}$ and $5 \mathrm{D}$ fibres (Table 2 ) in conjunction to their superior geometry (Fig. 1). Despite the 3D fibres series having the greater number of $\mathrm{N}_{\text {eff, }}$ the highest values of $\sigma_{\text {peak }}$ is observed for $4 \mathrm{D}$ and $5 \mathrm{D}$ fibres. For the fibre content of $0.5 \%$, the average value of $\mathrm{N}_{\text {eff }}$ for $3 \mathrm{D}, 4 \mathrm{D}$ and $5 \mathrm{D}$ fibres are 26,16 and 8 , 
and the corresponding values of $\sigma_{\text {peak }}$ are $2.15,2.59$ and $2.85 \mathrm{MPa}$, respectively. In the case of fibre content of $1 \%$, the average number of $N_{\text {eff }}$ for 3D, 4D and 5D fibres are 48, 28 and 15 , and the corresponding values of $\sigma_{\text {peak }}$ are $3.62,4.56$ and $6.87 \mathrm{MPa}$, respectively. These indicate that the anchorage strength is the most important parameter affecting the postcracking response, regardless of the number of fibres that bridge the cracked surfaces.

\section{Conclusions}

In this paper, the tensile behaviour of steel fibre reinforced self-compacting concrete (SFRC) was assessed by a uniaxial tensile test. Three types of hooked-end steel fibre with different geometries at the fibre dosage of 0.5 and $1 \%$ were investigated and the following main conclusions were gathered:

1) For all specimens reinforced with hooked-end steel fibres, the stress-crack width response was almost linear up to the load at crack initiation and a smooth transition in the post-peak region was observed. Specimens reinforced with 5D fibres presented a plateau response in the post-peak region.

2) The increase in the number of hook ends has a positive influence on the pull-out behaviour, whereas 5D fibre shows the highest pull-out strength compared with 3D and 4D fibres.

3) The Peak and post-peak response remarkably increased with an increase in the hook ends, where 5D fibres specimens showed the highest values of peak and post-peak strength.

4) While increasing fibre dosage was necessary for improving the post-cracking response, increasing the number of fibres at the cracked sections did not necessarily lead to enhanced post-peak behaviour. Although, specimens reinforced with 3D fibres had a much high number of effective fibres, the peak and post-peak strength of 4D and 5D fibres were significantly higher. 
5) The fibre rupture was observed only for specimens reinforced with the 3D fibres. For the $4 \mathrm{D}$ and $5 \mathrm{D}$ fibres, only a partial straightening of the hook occurred due to the imbalance between the moderate concrete strength and high anchorage strength of these fibres. To fully utilize the high mechanical anchorage, 5DH fibres should be used for reinforcing matrix with higher strength.

\section{Acknowledgments}

The first author is grateful for the financial support provided by the Ministry of Higher Education and Scientific Research of the Iraqi Government.

Reference List

[1] D. Wang, C. Shi, Z. Wu, J. Xiao, Z. Huang, Z. Fang, A review on ultra high performance concrete: Part II. Hydration, microstructure and properties, Constr. Build. Mater. 96 (2015) 368-377.

[2] R. Siddique, G. Kaur, Strength and permeation properties of self-compacting concrete containing fly ash and hooked steel fibres, Constr. Build. Mater. 103 (2016) 15-22.

[3] T. Abu-Lebdeh, S. Hamoush, W. Heard, B. Zornig, Effect of matrix strength on pullout behavior of steel fiber reinforced very-high strength concrete composites, Constr. Build. Mater. 25 (2011) 39-46.

[4] T. Soetens, S. Matthys, Different methods to model the post-cracking behaviour of hooked-end steel fibre reinforced concrete, Constr. Build. Mater. 73 (2014) 458-471.

[5] S. Abdallah, M. Fan, D.W.A. Rees, Effect of elevated temperature on pull-out behaviour of 4DH/5DH hooked end steel fibres, Composite Structures. 165 (2017) 180-191.

[6] S. Lee, J. Won, Flexural behavior of precast reinforced concrete composite members reinforced with structural nano-synthetic and steel fibers, Composite Structures. 118 (2014) 571-579.

[7] A. Beglarigale, H. Yazıcı, Pull-out behavior of steel fiber embedded in flowable RPC and ordinary mortar, Constr. Build. Mater. 75 (2015) 255-265.

[8] V.P. Villar, N.F. Medina, Alignment of hooked-end fibres in matrices with similar rheological behaviour to cementitious composites through homogeneous magnetic fields, Constr. Build. Mater. 163 (2018) 256-266. 
[9] Y. Hao, H. Hao, Pull-out behaviour of spiral-shaped steel fibres from normal-strength concrete matrix, Constr. Build. Mater. 139 (2017) 34-44.

[10] S. Abdallah, M. Fan, D.W. Rees, Bonding Mechanisms and Strength of Steel Fiber-Reinforced Cementitious Composites: Overview, J. Mater. Civ. Eng. 30 (2018) 04018001.

[11] M. di Prisco, M. Colombo, D. Dozio, Fibre-reinforced concrete in fib Model Code 2010: principles, models and test validation, Structural Concrete. 14 (2013) 342-361.

[12] K. Wille, S. El-Tawil, A.E. Naaman, Properties of strain hardening ultra high performance fiber reinforced concrete (UHP-FRC) under direct tensile loading, Cement and Concrete Composites. 48 (2014) 53-66.

[13] S. Abdallah, M. Fan, Anchorage mechanisms of novel geometrical hooked-end steel fibres, Mater. Struct. 50 (2017) 139.

[14] M. Tuyan, H. YazıCI, Pull-out behavior of single steel fiber from SIFCON matrix, Constr. Build. Mater. 35 (2012) 571-577.

[15] T. Soetens, A. Van Gysel, S. Matthys, L. Taerwe, A semi-analytical model to predict the pull-out behaviour of inclined hooked-end steel fibres, Constr. Build. Mater. 43 (2013) 253-265.

[16] J. Domski, J. Katzer, M. Zakrzewski, T. Ponikiewski, Comparison of the mechanical characteristics of engineered and waste steel fiber used as reinforcement for concrete, J. Clean. Prod. 158 (2017) $18-28$.

[17] S. Abdallah, M. Fan, X. Zhou, Pull-Out Behaviour of Hooked End Steel Fibres Embedded in Ultrahigh Performance Mortar with Various W/B Ratios, International Journal of Concrete Structures and Materials. (2017) 1-13.

[18] M. Pająk, T. Ponikiewski, Flexural behavior of self-compacting concrete reinforced with different types of steel fibers, Constr. Build. Mater. 47 (2013) 397-408.

[19] S. Abdallah, M. Fan, K.A. Cashell, Pull-out behaviour of straight and hooked-end steel fibres under elevated temperatures, Cem. Concr. Res. 95 (2017) 132-140.

[20] S. Abdallah, M. Fan, D.W.A. Rees, Analysis and modelling of mechanical anchorage of 4D/5D hooked end steel fibres, Mater Des. 112 (2016) 539-552.

[21] S. Abdallah, M. Fan, K.A. Cashell, Bond-slip behaviour of steel fibres in concrete after exposure to elevated temperatures, Constr. Build. Mater. 140 (2017) 542-551.

[22] M. Pająk, T. Ponikiewski, Investigation on concrete reinforced with two types of hooked fibers under flexure, Procedia engineering. 193 (2017) 128-135.

[23] M. Alberti, A. Enfedaque, J. Gálvez, Fibre reinforced concrete with a combination of polyolefin and steel-hooked fibres, Composite Structures. 171 (2017) 317-325.

[24] V. Afroughsabet, L. Biolzi, T. Ozbakkaloglu, Influence of double hooked-end steel fibers and slag on mechanical and durability properties of high performance recycled aggregate concrete, Composite Structures. 181 (2017) 273-284. 
[25] A. Khabaz, Monitoring of impact of hooked ends on mechanical behavior of steel fiber in

428 concrete, Constr. Build. Mater. 113 (2016) 857-863.

429 [26] K. Georgiadi-Stefanidi, E. Mistakidis, D. Pantousa, M. Zygomalas, Numerical modelling of the 430 pull-out of hooked steel fibres from high-strength cementitious matrix, supplemented by 431 experimental results, Constr. Build. Mater. 24 (2010) 2489-2506.

432 [27] J. Feng, W. Sun, X. Wang, X. Shi, Mechanical analyses of hooked fiber pullout performance in ultra-high-performance concrete, Constr. Build. Mater. 69 (2014) 403-410.

434 [28] ACl Committee, Design Considerations for Steel Fiber Reinforced Concrete (ACl 544.4 R-88), 435 (1988) 18-18.

436 [29] ACl Committee, American Concrete Institute, International Organization for Standardization, 437 Building code requirements for structural concrete (ACl 318-08) and commentary, (2008).

438 [30] R. TC162-TDF, Test and Design Methods for Steel Fibre Reinforced Concrete Structures, Mater. 439 Struct. 35 (2002) 262-278.

440 [31] D. CNR, 204/2006.(2006). Guidelines for the design, construction and production control of fibre 441 reinforced concrete structures, National Research Council of Italy. 59.

442 [32] D.A. für Stahlbeton, Guidelines for steel fiber reinforced concrete-23th Draft-richtlinie 443 Stahlfaserbeton-DIN 1045 Annex parts 1-4, (2007).

444 [33] D.H.E. INSTRUCCIÓN, EHE-08, Catálogo de publicaciones del Ministerio de Fomento Año. (2008).

445 [34] A. Abrishambaf, J.A.O. Barros, V.M.C.F. Cunha, Relation between fibre distribution and post446 cracking behaviour in steel fibre reinforced self-compacting concrete panels, Cem. Concr. Res. 51 447 (2013) 57-66.

[35] S. Abdallah, M. Fan, X. Zhou, S. Geyt, Anchorage Effects of Various Steel Fibre Architectures for 449 Concrete Reinforcement, International Journal of Concrete Structures and Materials. (2016) 1-11.

450 [36] F. Bencardino, L. Rizzuti, G. Spadea, R.N. Swamy, Experimental evaluation of fiber reinforced 451 concrete fracture properties, Composites Part B: Engineering. 41 (2010) 17-24.

[37] F. Laranjeira de Oliveira, Design-oriented constitutive model for steel fiber reinforced concrete, Unpublished Doctoral dissertation. Universitat Politècnica de Catalunya, Spain. (2010).

454 [38] A.G. Kooiman, Modelling steel fibre reinforced concrete for structural design, (2000).

455 [39] B.E. Barragán, Failure and Toughness of Steel Fiber Reinforced Concrete Under Tension and 456 Shear, Universitat Politècnica de Catalunya, 2002.

457 [40] L. Vandewalle, RILEM TC 162-TDF: Test and design methods for steel fibre reinforced concrete, 458 Mater. Struct. 33 (2000) 3-6. 
461 [43] S. Nagataki, H. Fujiwara, Self-compacting property of highly flowable concrete, Special

462 Publication. 154 (1995) 301-314.

463 [44] T. Ponikiewski, J. Katzer, M. Bugdol, M. Rudzki, Steel fibre spacing in self-compacting concrete 464 precast walls by X-ray computed tomography, Mater. Struct. 48 (2015) 3863-3874.

465 [45] B. EN, 197-1: 2011, Cement, Composition, Specifications and Conformity Criteria for Common 466 Cements.London, England: British Standard Institution (BSI). (2011).

467 [46] Y. Lee, S. Kang, J. Kim, Pullout behavior of inclined steel fiber in an ultra-high strength 468 cementitious matrix, Constr. Build. Mater. 24 (2010) 2030-2041.

469 [47] V.M. Cunha, Steel fibre reinforced self-compacting concrete (from micromechanics to 470 composite behavior), (2010).

471 
Table 1

474 Mixture proportion per $1 \mathrm{~m}^{3}$ of concrete made

\begin{tabular}{cccccccc} 
Cement & $\begin{array}{l}\text { Fly } \\
\text { ash }\end{array}$ & $\begin{array}{c}\text { Sand } \\
(0-2 \mathrm{~mm})\end{array}$ & $\begin{array}{c}\text { Coarse } \\
\text { aggregate } \\
(6-10) \mathrm{mm}\end{array}$ & $\begin{array}{l}\text { Steel fibres } \\
\left(\mathrm{kg} / \mathrm{m}^{3}\right)\end{array}$ & $\begin{array}{l}\text { Superplasticizer } \\
\left(\mathrm{kg} / \mathrm{m}^{3}\right)\end{array}$ & $\begin{array}{l}\text { Water } \\
\left(\mathrm{kg} / \mathrm{m}^{3}\right)\end{array}$ & $\begin{array}{l}475 \\
\mathrm{~W} / \mathrm{C}\end{array}$ \\
$47 \mathrm{~F} 6$ \\
\hline 40 & 45 & 850 & 886 & 40 and 80 & 6 & 216 & 0.472 \\
\hline
\end{tabular}

478

479

480

Table 2

481

The measured geometric and mechanical properties of hooked-end fibres

\begin{tabular}{ccccccc}
\hline Fibre type & $\sigma_{\mathrm{u}}{ }^{*}$ & $l_{f}$ & $d_{f}$ & Hook length & Hook & Hook \\
& $(\mathrm{MPa})$ & $(\mathrm{mm})$ & $(\mathrm{mm})$ & $(\mathrm{mm})$ & angles $\left(^{\circ}\right)$ & height
\end{tabular}

$(\mathrm{mm})$

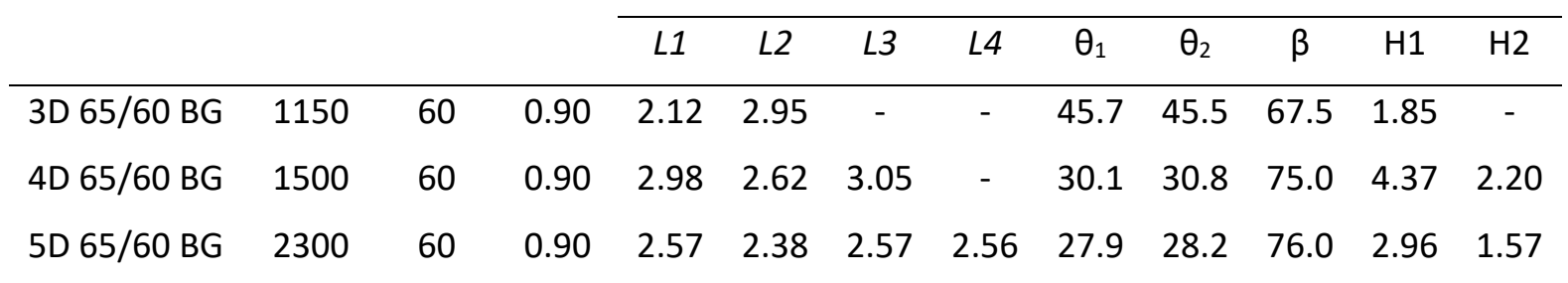

482

* Ultimate strength

483

484

485

486

Table 3

487 Rheological and mechanical properties results

\begin{tabular}{|c|c|c|c|c|c|c|}
\hline \multirow[t]{2}{*}{ Series } & \multicolumn{2}{|c|}{ Slump flow } & \multirow{2}{*}{$\begin{array}{c}\text { V-funnel } \\
T_{v}(s)\end{array}$} & \multirow{2}{*}{$\begin{array}{l}\text { Density } \\
\left(\mathrm{kg} / \mathrm{m}^{3}\right)\end{array}$} & \multirow{2}{*}{$\begin{array}{c}f_{c, 28}^{\prime} \\
(\mathrm{MPa})\end{array}$} & \multirow{2}{*}{$\begin{array}{l}\text { CoV } \\
(\%) \\
\end{array}$} \\
\hline & SFD $(\mathrm{mm})$ & $T_{500}(\mathrm{~s})$ & & & & \\
\hline $\mathrm{CM}$ & 710 & 2 & 7 & 2399 & 68.5 & 4.3 \\
\hline $3 D-40$ & 700 & 4 & 10 & 2360 & 67.7 & 5.4 \\
\hline $3 D-80$ & 695 & 5 & 13 & 2320 & 69.9 & 6.1 \\
\hline $4 D-40$ & 700 & 4 & 9 & 2368 & 66.4 & 7.5 \\
\hline $4 D-80$ & 695 & 6 & 14 & 2315 & 68.2 & 9.2 \\
\hline $5 D-40$ & 700 & 4 & 11 & 2350 & 70.8 & 4.9 \\
\hline $5 D-80$ & 690 & 5 & 15 & 2310 & 69.6 & 8.3 \\
\hline
\end{tabular}

488

489

490

491

492 
Table 4

494

Peak and post-peak parameters *

\begin{tabular}{|c|c|c|c|c|c|}
\hline Fibre type & $\begin{array}{c}\text { Fibre dosage } \\
\left(\mathrm{kg} / \mathrm{m}^{3}\right)\end{array}$ & $\sigma_{\text {peak }}(\mathrm{MPa})$ & $\delta_{\text {peak }}(\mu \mathrm{m})$ & $\sigma_{2000}(\mathrm{~Pa})$ & $\begin{array}{r}G_{F, 2000}(N / 495 \\
496 \\
497\end{array}$ \\
\hline $\mathrm{CM}$ & 0 & 0.25 & 5.4 & - & - 498 \\
\hline \multirow{2}{*}{$3 \mathrm{D}$} & 40 & 2.15 & 6.1 & 660000 & $0.0016 \frac{199}{500}$ \\
\hline & 80 & 3.62 & 9.7 & 2390000 & 0.0024501 \\
\hline \multirow{2}{*}{ 4D } & 40 & 2.59 & 5.7 & 850000 & 0.0019402 \\
\hline & 80 & 4.56 & 10.3 & 2400000 & $0.0028 \frac{504}{505}$ \\
\hline \multirow{2}{*}{$5 \mathrm{D}$} & 40 & 2.85 & 9.6 & 1690000 & $0.0036 \$ 06$ \\
\hline & 80 & 6.87 & 7.8 & 4450000 & $0.0054 Z 08$ \\
\hline
\end{tabular}

510

511

512 Table 5

513 Average number of fibres counted on different locations of fractured cross sections

\begin{tabular}{|c|c|c|c|c|c|c|}
\hline \multirow{2}{*}{ Mix } & \multicolumn{4}{|c|}{ Location } & \multirow{2}{*}{$\begin{array}{c}\mathrm{N}_{\text {total }} \\
\text { average }\end{array}$} & \multirow{2}{*}{$\frac{\mathrm{N}_{\mathrm{gf15}}}{\text { avefage }}$} \\
\hline & A & B & $C$ & D & & \\
\hline $3 D-40$ & $29 \%$ & $28 \%$ & $29 \%$ & $14 \%$ & 34 & 2517 \\
\hline $3 D-80$ & $29 \%$ & $27 \%$ & $35 \%$ & $9 \%$ & 58 & 48 \\
\hline $4 D-40$ & $31 \%$ & $34 \%$ & $21 \%$ & $14 \%$ & 28 & 1519 \\
\hline $4 D-80$ & $32 \%$ & $30 \%$ & $19 \%$ & $19 \%$ & 49 & 2320 \\
\hline $5 D-40$ & $25 \%$ & $34 \%$ & $23 \%$ & $18 \%$ & 24 & $\$ 21$ \\
\hline $5 D-80$ & $15 \%$ & $38 \%$ & $35 \%$ & $12 \%$ & 44 & 1522 \\
\hline
\end{tabular}




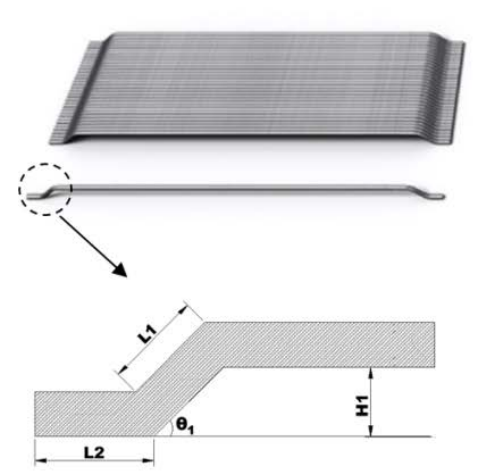

\section{D}

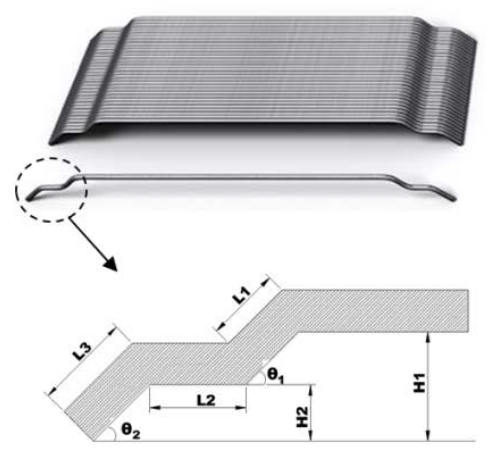

\section{D}

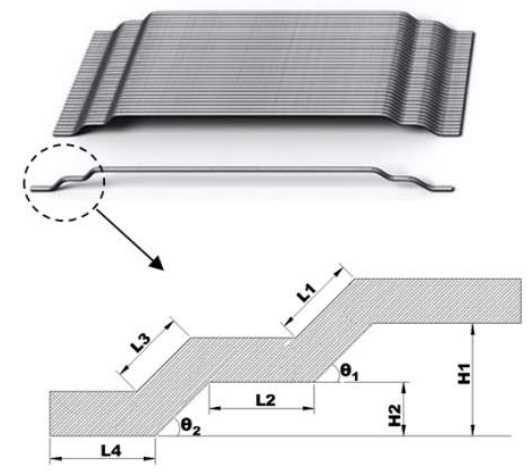

5D
523

524

525

526

527

528

529

Fig. 1. Geometrical properties of hooked end steel fibres

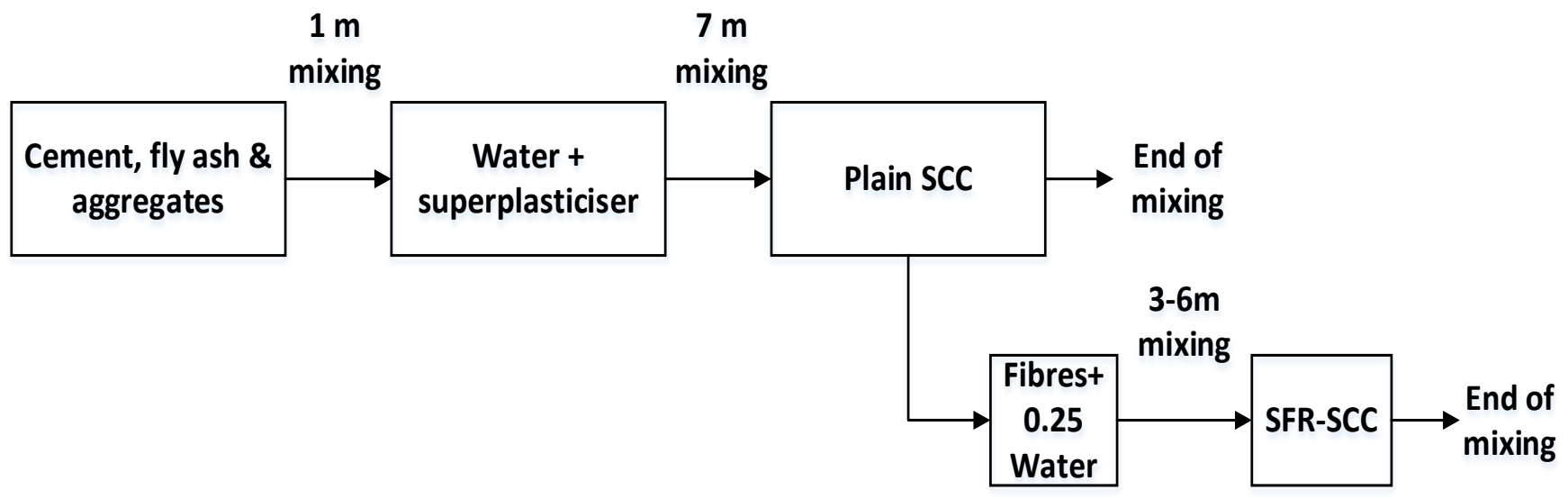

Fig. 2. Mixing protocol of SCC and SFR-SCC 


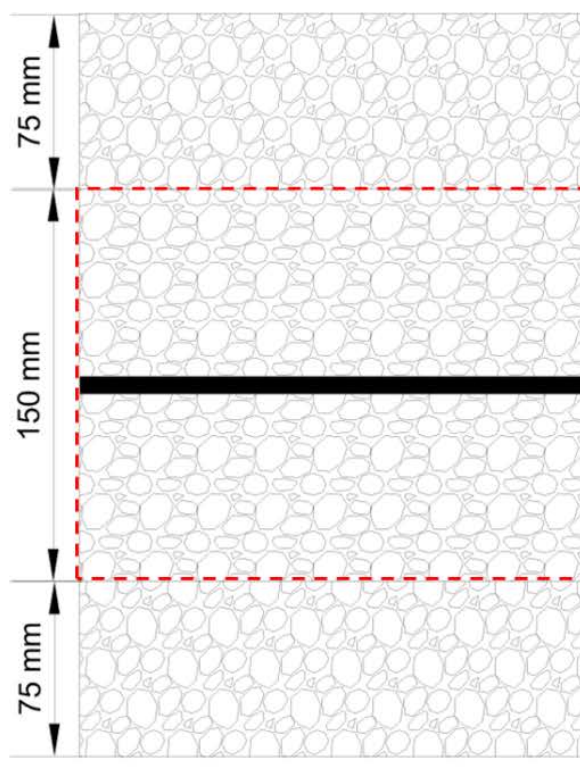

(a) Original sample

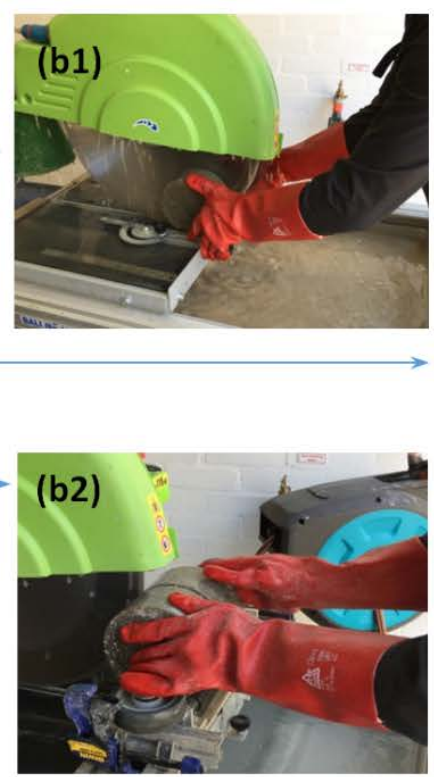

(b) Sawing process

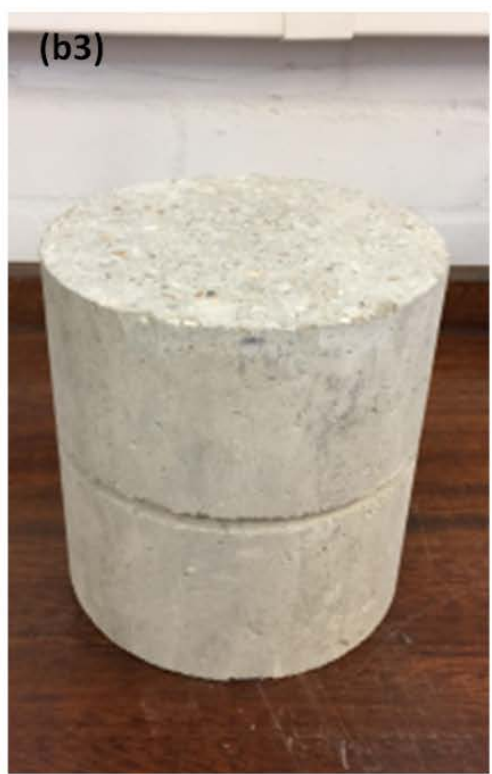

539

Fig. 3. Geometrical details of the specimen to be tested in the uniaxial tensile test 


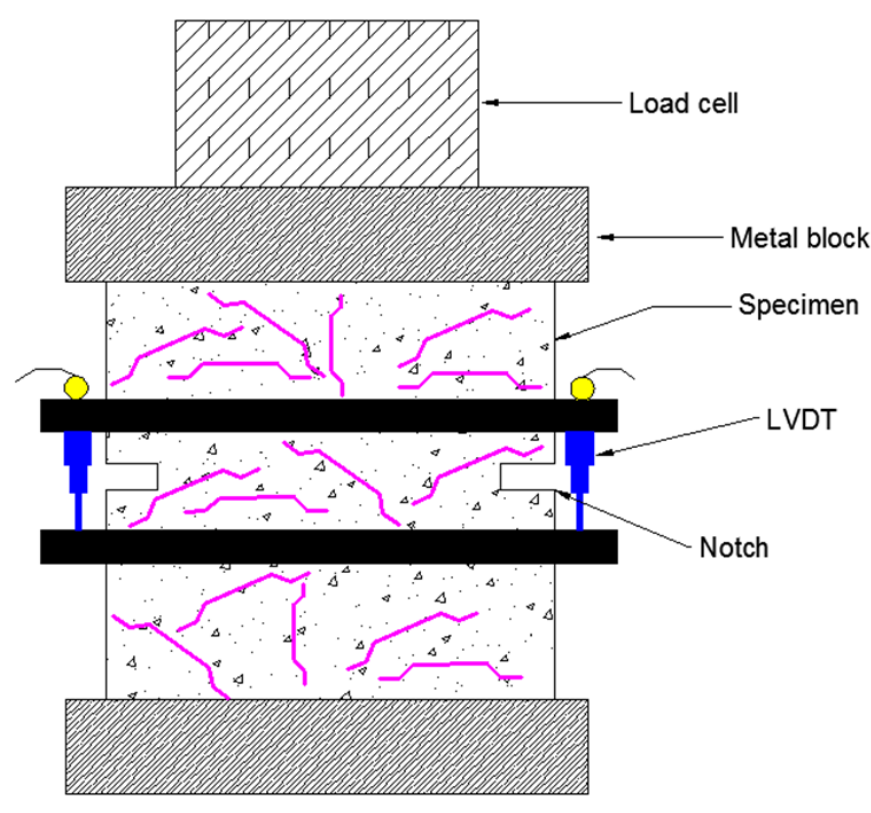

(a)

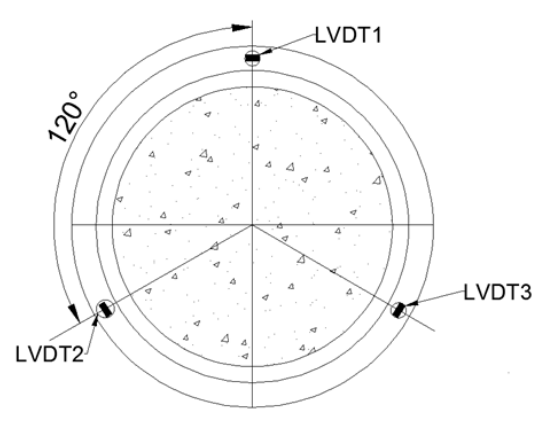

(b)
550

551 552

553

554

Fig. 4. Uniaxial tension test set-up: general view (a) and positioning of displacement transducers (b)

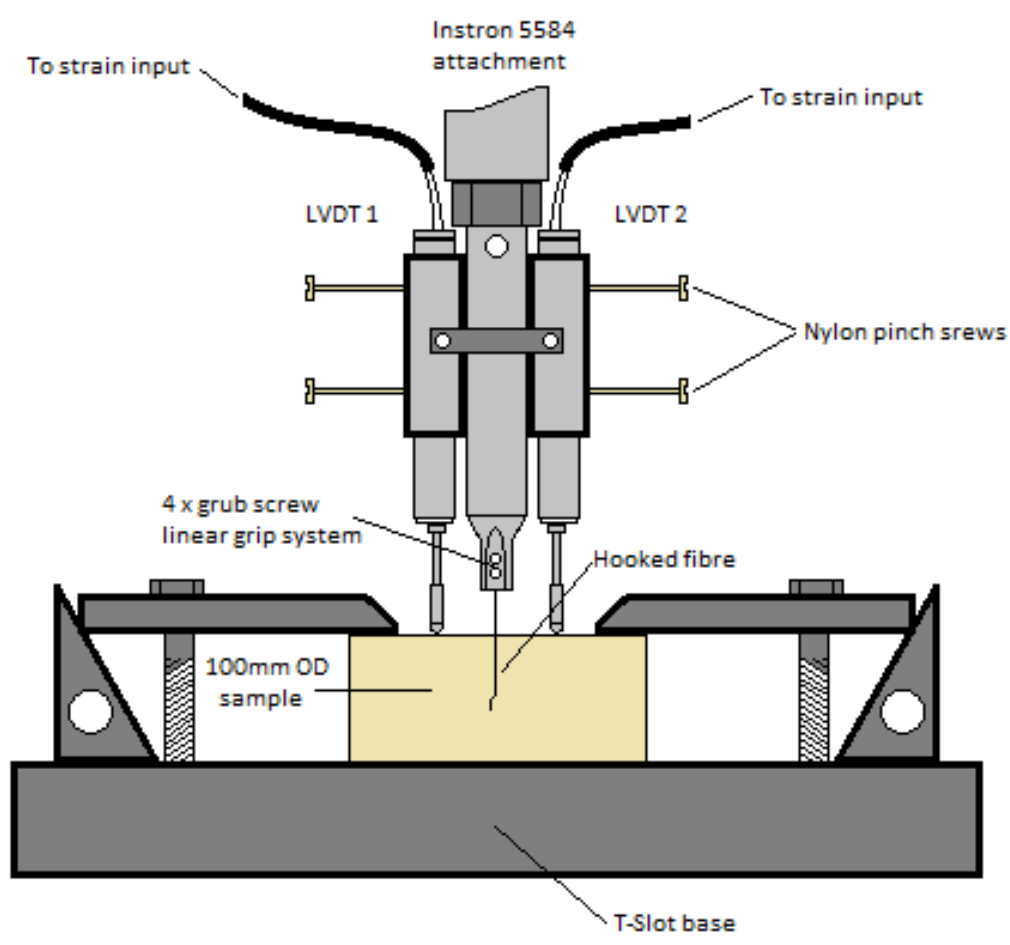

555

Fig. 5. Pull-out test setup 


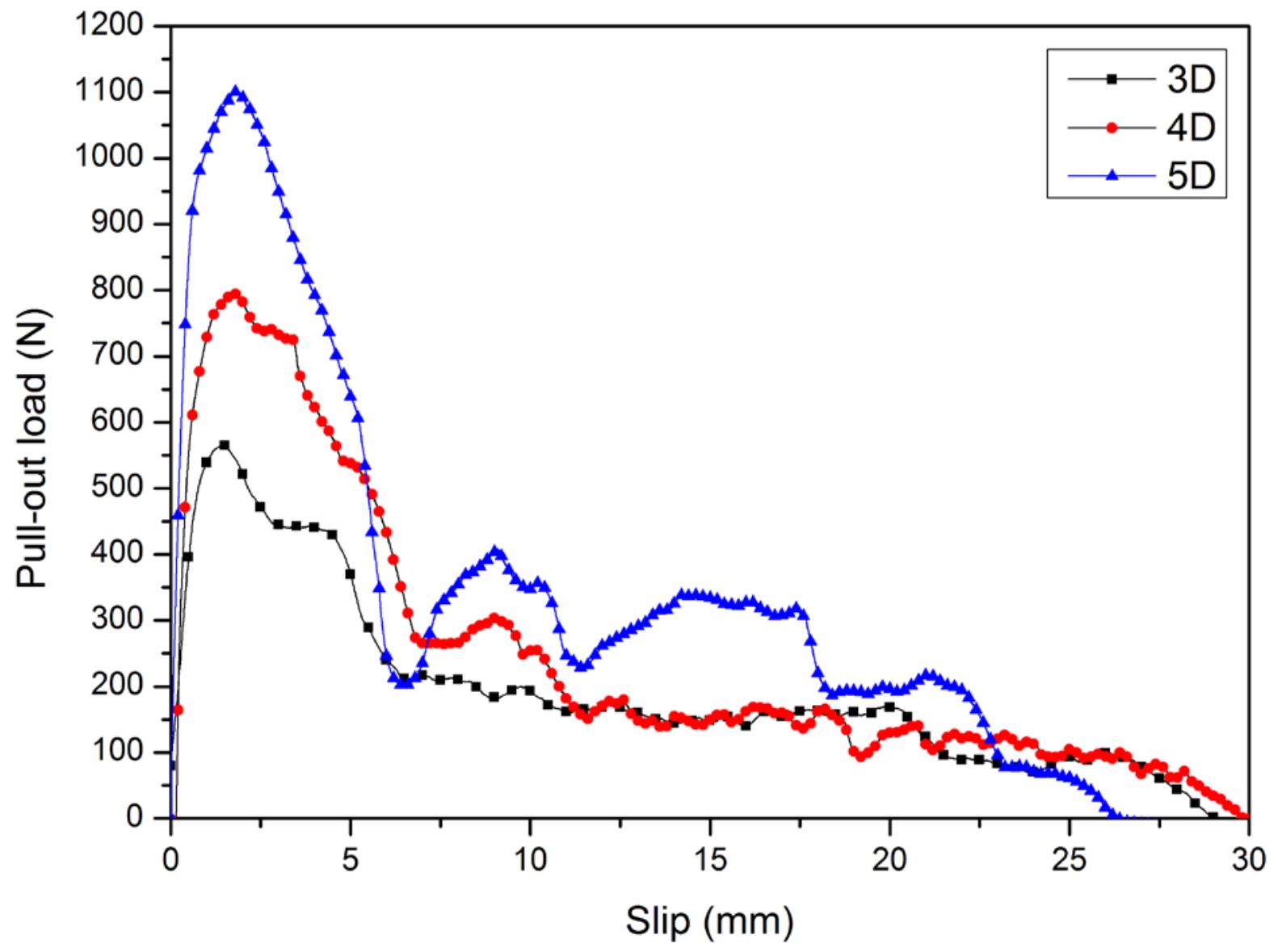

Fig. 6. Average pull-out-slip response of 3D, 4D and 5D fibres

559

560

561

562

563

564

565

566

567

568

569

570

571 


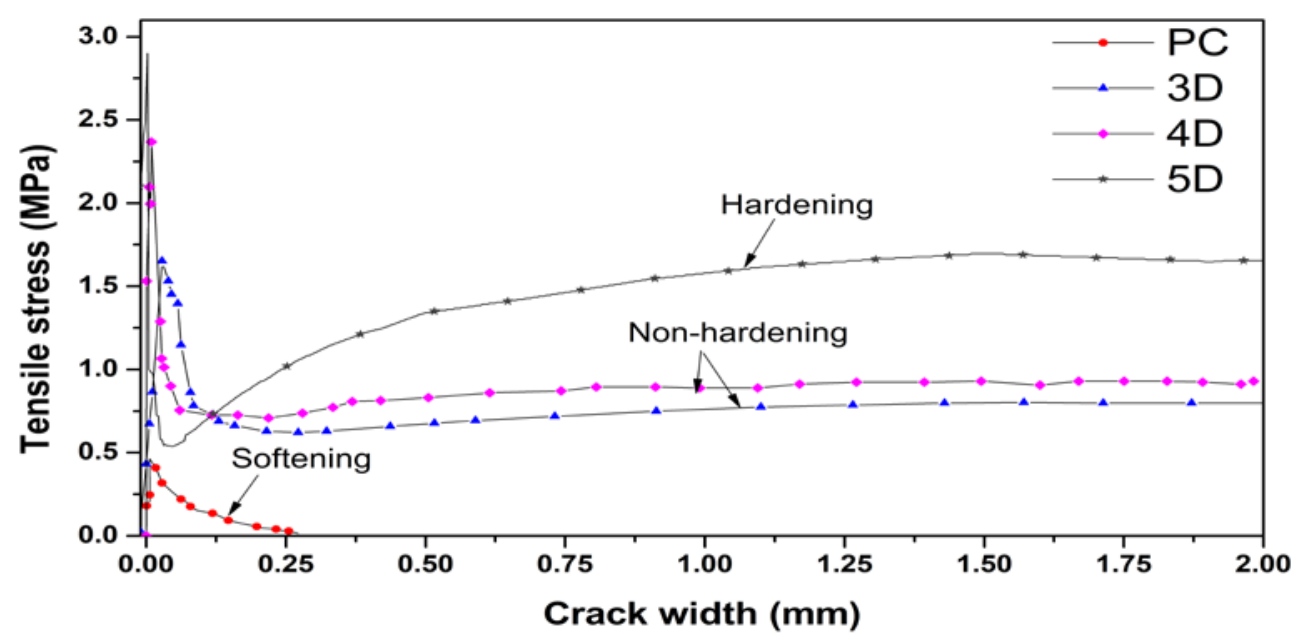

(a)

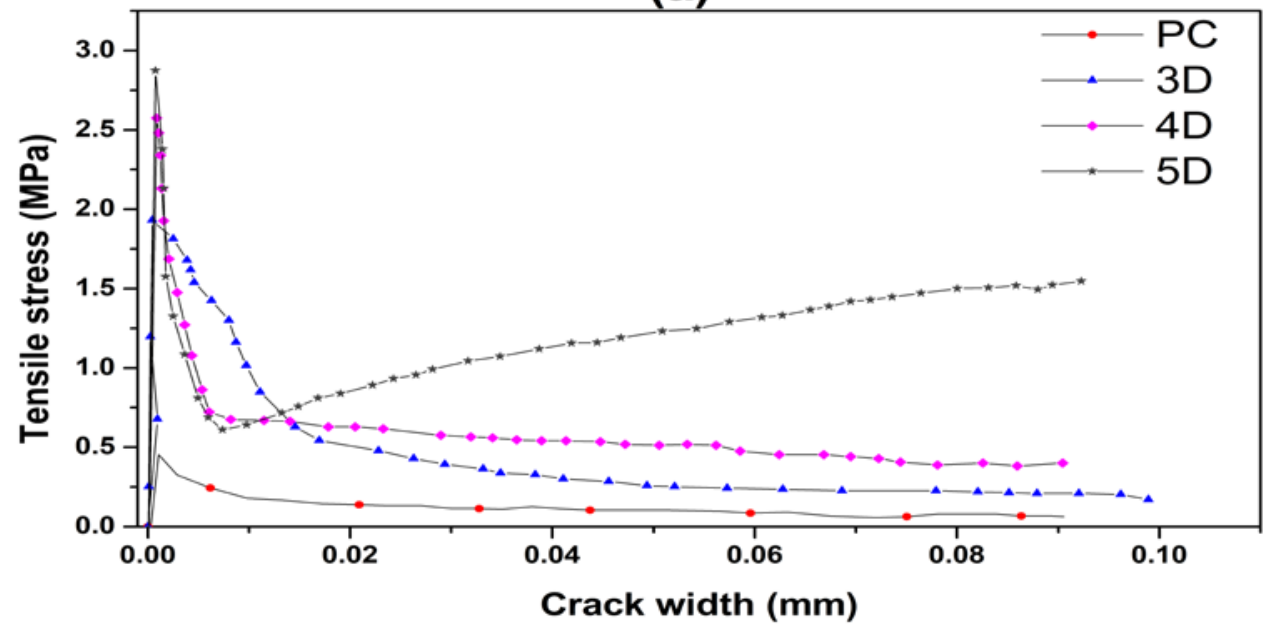

(b)

Fig. 7. .Average stress-crack width responses of SFR-SCC series reinforced with $40 \mathrm{~kg}$ fibres: (a) total 


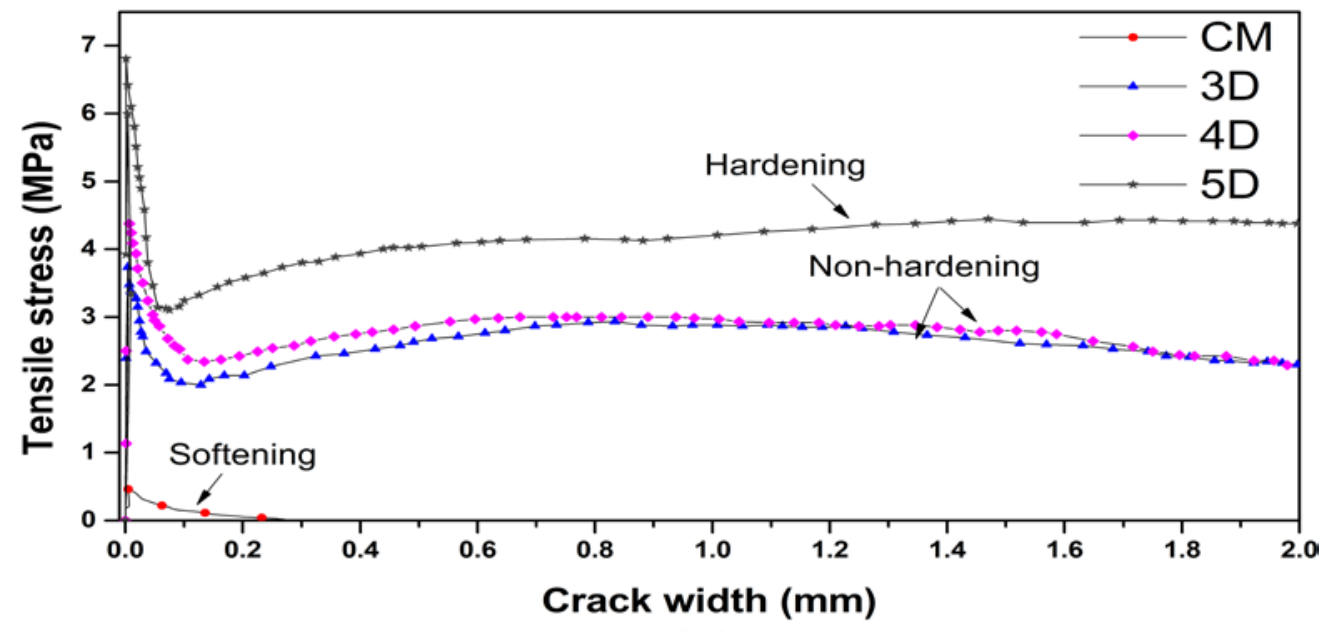

(a)

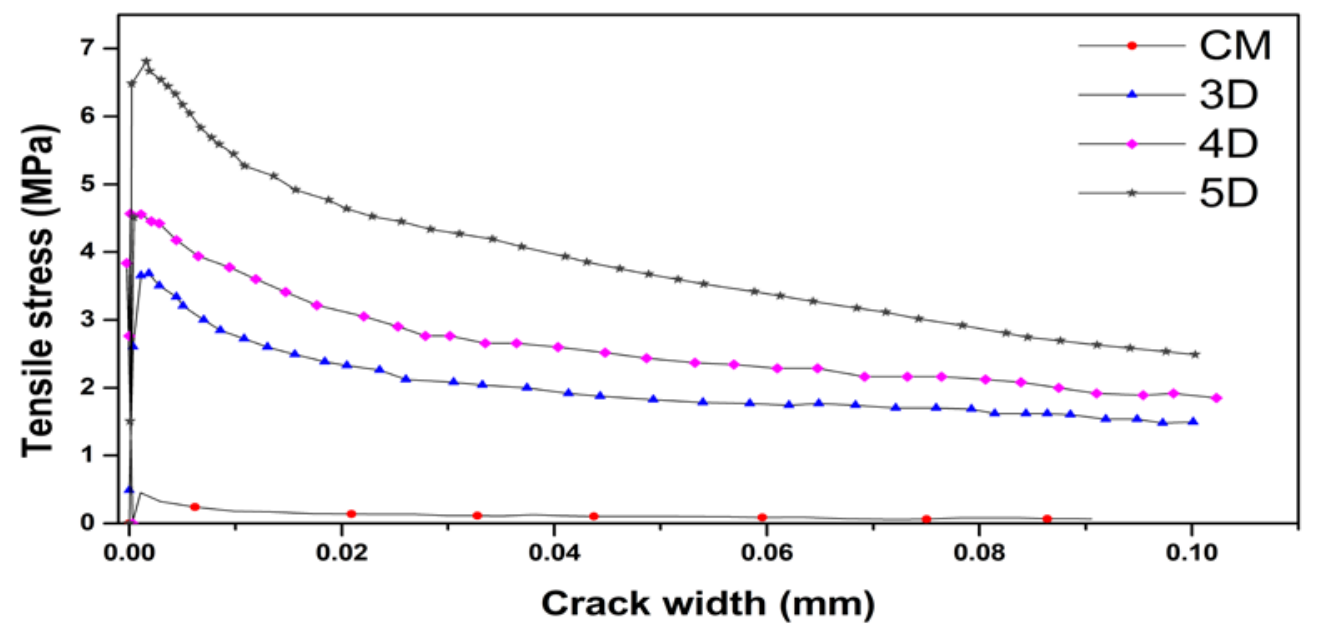

(b)

Fig. 8. Average stress-crack width responses of SFR-SCC series reinforced with $80 \mathrm{~kg}$ fibres: (a) total stress-crack width curve and (b) detailed up to a crack width of $0.1 \mathrm{~mm}$ 


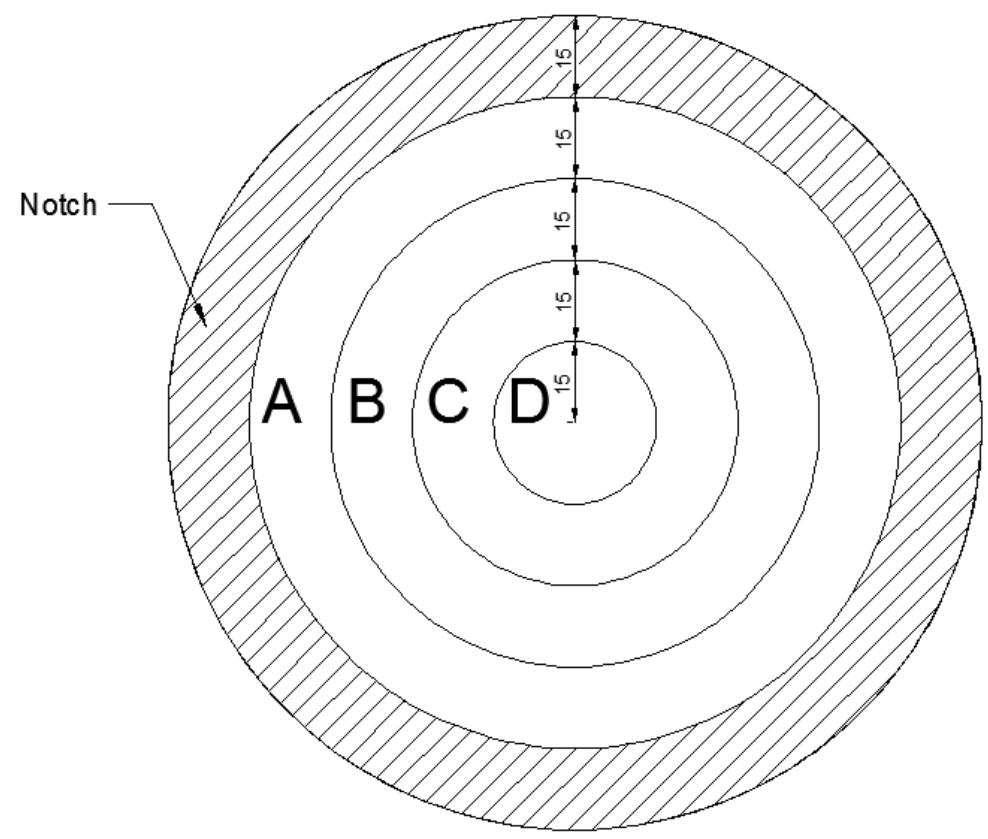

Fig. 9. Cross-sectional surface shows analysis of the fibre distribution in the different domains
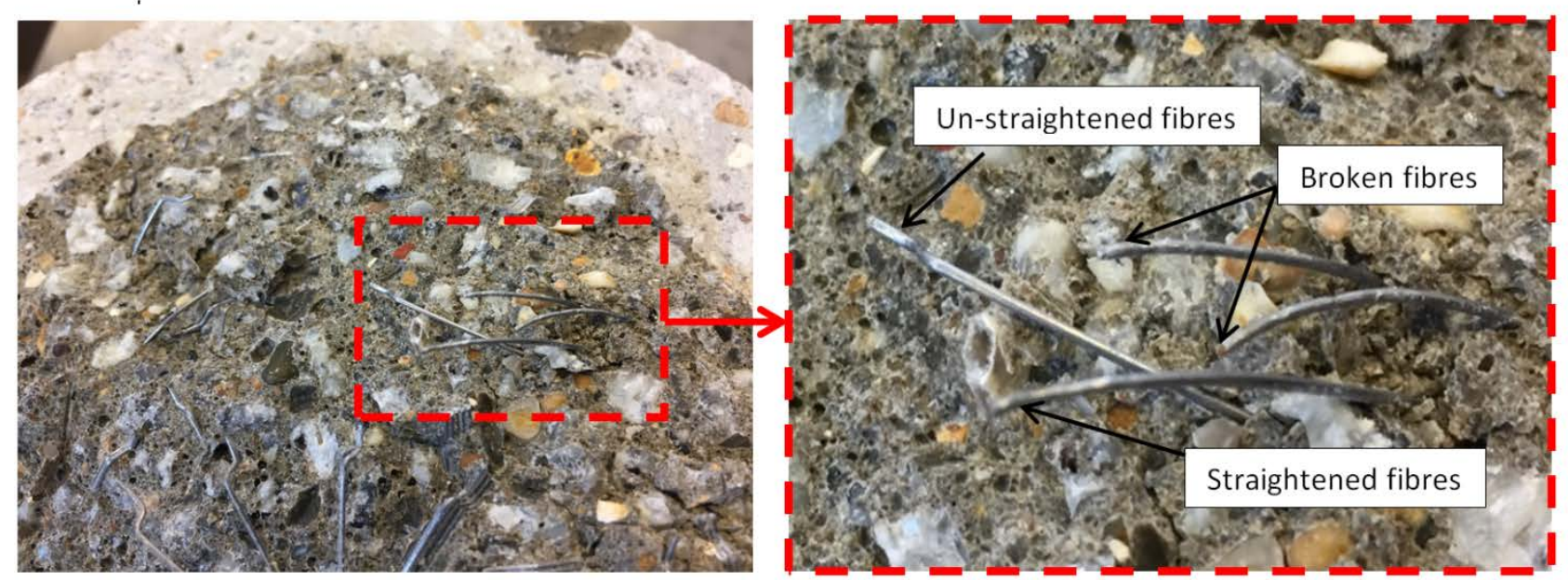

600

Fig. 10. Pull-out pattern of 3D fibres

601

602

603 


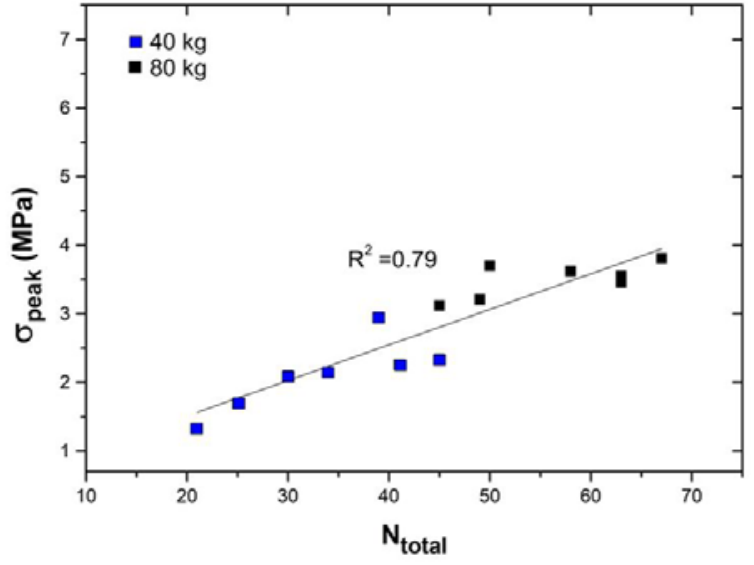

(a)

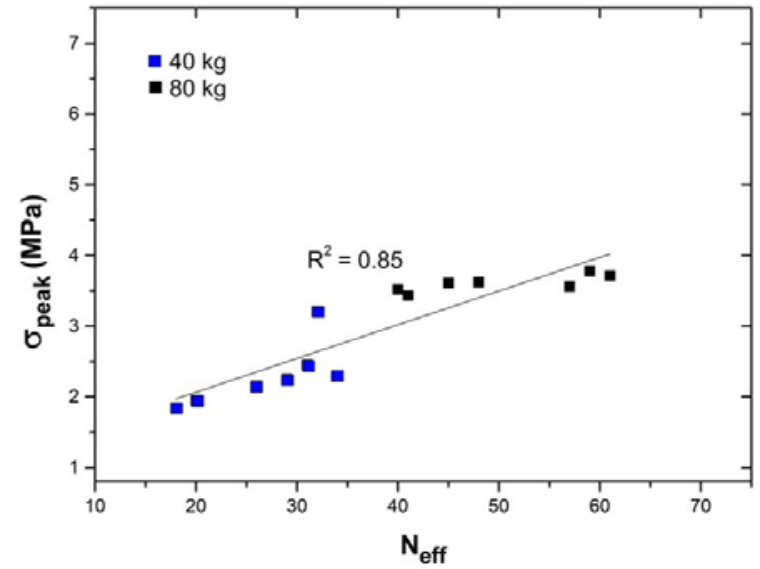

(b)
605

606

607

608

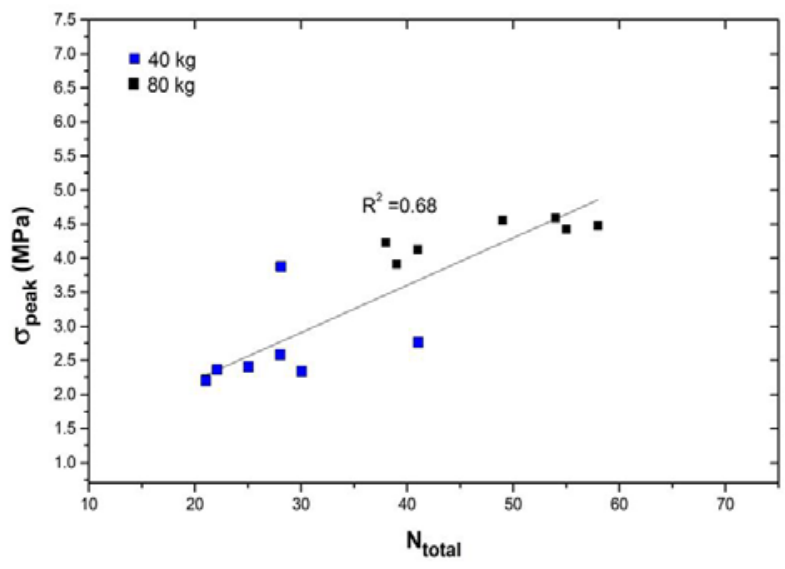

(a) Total number $\left(\mathrm{N}_{\text {total }}\right)$ and (b) Effective fibres $\left(\mathrm{N}_{\text {eff }}\right)$.

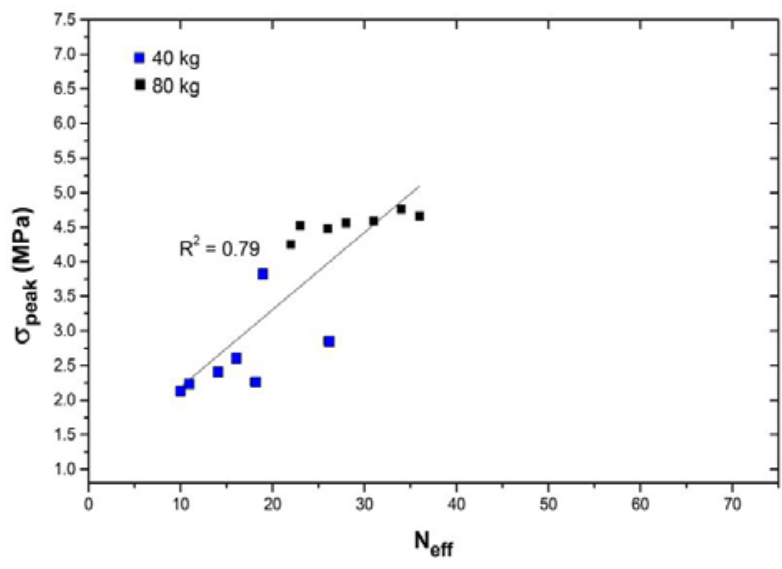

(b)

Fig. 11. Relationship between the $\sigma_{\text {peak }}$ and number of fibres in the fracture surfaces of 3D fibres:(a)

610 Fig. 2. Relationship between the $\sigma_{\text {peak }}$ and number of fibres in the fracture surfaces of 4D fibres: (a) Total number $\left(\mathrm{N}_{\text {total }}\right)$ and (b) Effective fibres $\left(\mathrm{N}_{\text {eff }}\right)$. 


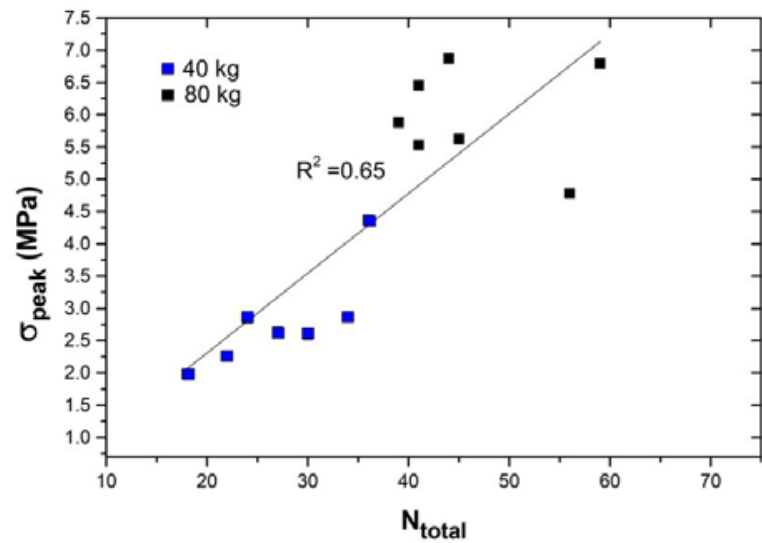

(a)

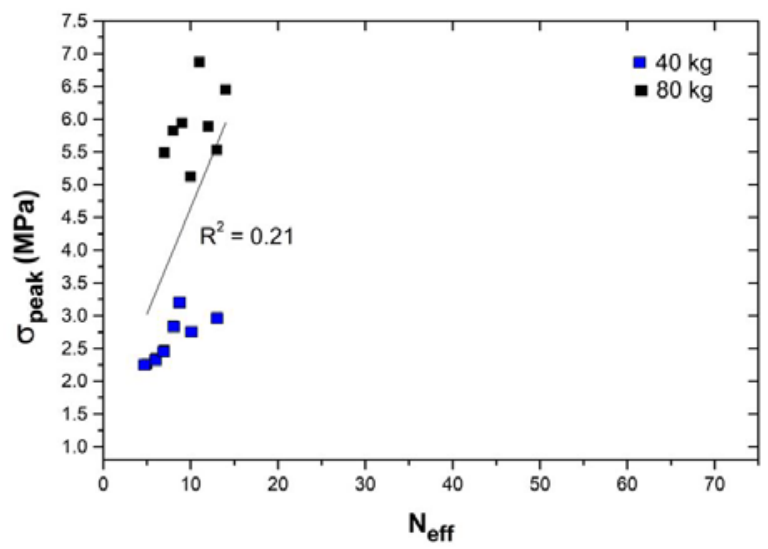

(b)

614

Fig. 3. Relationship between the $\sigma_{\text {peak }}$ and number of fibres in the fracture surfaces of 5D fibres: (a) 615 Total number $\left(\mathrm{N}_{\text {total }}\right)$ and (b) Effective fibres $\left(\mathrm{N}_{\text {eff }}\right)$ 